\title{
¿QUÉ SIGNIFICA PENSAR TRAS EL GIRO LINGÜÍSTICO? LA FILOSOFÍA DE ERNST TUGENDHAT*
}

\author{
Santiago ZABALA \\ Pontificia Universidad Lateranense de Roma
}

\begin{abstract}
RESUMEN. En este artículo se evalúa la significación, en la filosofía contemporánea, de la filosofía de Ernst Tugendhat y su denominado "giro" desde la fenomenología hacia la filosoffa analítica. Según este análisis, Tugendhat no sólo es el más importante de los discípulos de Heidegger, en compañía de Hans-Georg Gadamer, sino, sobre todo, aquel que liquida por fin la labor metafísica de la filosofía, gracias al análisis lingüístico. Así como Gadamer «urbanizó" la ontología heideggeriana (en palabras de Habermas), por su parte Tugendhat la ha «semantizado". Pero ¿cómo se ha producido esta semantización? No fue con el giro lingüístico del siglo XX, sino desde sus inicios, por cuanto la ontologia ha sido siempre un análisis lingüístico inconsciente. Tras analizar los textos más relevantes de Tugendhat, se muestra la importancia del pensamiento fregeano $y$ wittgensteiniano para la elaboración por parte de éste de una kontología semántica", capaz de resolver/disolver el problema del Ser. La conclusión de este artículo sobre la disolución lingüística de la ontología muestra, por una parte, que para Tugendhat no hay hechos, sino sólo proposiciones verdaderas; pero además, por otro lado, se evidencia que el "lenguaje» debería considerarse como la auténtica consciencia del ser humano.
\end{abstract}

A Ugo Ugazio y Gianni Vattimo

\section{El giro lingüístico es el final de la metafísica}

Cuando hablamos del fin de la metafísica, bien sea en el sentido de Heidegger y Nietzsche o en el de Dewey y Rorty, conviene abandonar por una par-

* Traducción a cargo de Gorka Fernández Villarón. Revisada por Teresa Onate. 
te la idea de que podamos conocer el sentido de las palabras observando algo, y por otra la idea de que exista un vocabulario último que no sea ya ni revisable ni sustituible. En la filosofía contemporánea, la marcada separación entre analíticos y continentales ha terminado por crear una atmósfera en la que la imposibilidad de la metafísica y de su superación son percibidas únicamente como la premisa de una cultura filosófica del diálogo, de las fusiones. La renovación de la filosofía a través de la superación de la metafísica consiste en el éxito del giro lingüístico, esto es, de la idea de que el a priori lingüístico sea la forma de estructuración de la experiencia. Ernst Tugendhat es el ejemplo paradigmático de este giro si se le identifica no dentro de la división entre analíticos y continentales (división que ya se está disolviendo), sino dentro de la cultura gadameriana del diálogo. La renovación de la filosofía a través de la Verwindung de la metafísica está determinada en gran parte por el éxito del giro lingüístico, o sea, por el éxito de la idea de que el a priori lingüístico es la forma de estructuración de la experiencia misma. Tugendhat, en la medida en que mantiene gadamerianamente abierto el diálogo entre la filosofía analítica del lenguaje y la tradición europea, es el ejemplo paradigmático del alcance del giro. Vattimo sostiene que

finalmente se ha convertido en una banalidad decir que la división entre filósofos "analíticos» (seguidores del Círculo de Viena y de Wittgenstein) y "continentales" (fenomenólogos, existencialistas, hermenéuticos) ya no subsiste, si es que alguna vez ha existido. [...] Por ambas partes ha habido una progresiva toma de distancia de las motivaciones racionalistas de la filosofía moderna, y en general de la predilección exclusiva de ésta por el problema del conocimiento. En suma, de la duda cartesiana, incluso en la versión que de ella tuvo Husserl. [...] Es como decir que (a la manera en que le objetaba ya Hegel a Descartes) toda reflexión crítica sucede dentro de una condición histórica que la hace posible y le proporciona sustrato y soporte. Ahora bien, es justamente sobre la base de esta nueva comprensión de la historicidad de todo conocer como se ha ido disolviendo poco a poco la división entre analíticos y continentales; incluso cuando en ambos campos todavía queda mucho por hacer a fin de desarrollar hasta el final todas las consecuencias de ello. ${ }^{1}$

1 G. VATtimo, «Pensiamo in compagnia», en L'espresso, n. 45, año XLVII (8-11-01), p. 193. 
La filosofía, en realidad, entra en una condición en la cual ya no tiene más "descubrimientos" que hacer, sino más bien sólo "análisis", pues sigue el programa del análisis lingüístico en sus funciones principalmente disolutivas o terapéuticas respecto de los problemas filosóficos; y en todo caso no tiene ninguna relevancia "material", en el sentido de que no corresponde por principio a ninguna elección ontológica, sino que se trata sólo de sentar las bases del método.

Que la verdad no tenga lugar en el plano de los hechos sino sólo en el plano de los enunciados es sin más la koiné cultural que caracteriza el fin de la metafísica tradicional y la llegada de la cultura gadameriana del diálogo, en la cual tanto analíticos como continentales puedan alcanzar en el lenguaje precisamente un lugar de encuentro. Tugendhat es el ejemplo paradigmático de ello al mostrar como, en la terminología de la ontología tradicional, el ser ha sido entendido primordialmente desde una perspectiva marcada por los objetos, y debe ahora comprenderse de nuevo como problema lingüístico. Con la filosofía analítica la comprensión ya no necesita representaciones ópticas, igual que el lenguaje ya no se presenta como fundado principalmente sobre expresiones nominales.

El pensamiento de Tugendhat está especialmente inspirado en la filosofía de Heidegger, de quien no sólo ha sido alumno directo en Friburgo, sino también sucesor directo; Tugendhat ha usado la filosofía analítica principalmente para tematizar problemas heideggerianos. Si Gadamer ha "urbanizado" la ontología heideggeriana, podemos afirmar que Tugendhat la ha «semantizado". ¿En qué ha consistido esta "semantización"? Según Heidegger el problema de la "comprensión» se debe entender como el problema de la "comprensión del ser", y una comprensión del ser es siempre también una comprensión del Nichts. Heidegger comparte con la tradición, como hace notar Tugendhat, la tendencia a la nominalización: el Nichts de Heidegger proviene él mismo de la expresión lingüística nicht, que debe ser entendida en primer lugar como función predicativa. El problema ontológico planteado en Sein und Zeit debe mantenerse rigurosamente en el plano del lenguaje (del sentido, de la verdad). Es esto lo que Tugendhat ha llevado a cabo en el diálogo que ha mantenido con Heidegger. Tugendhat sostiene que toda la ontología, desde los orígenes preplatónicos hasta Heidegger, ha sido siempre una indagación lingüística inconsciente; no obstante, se malinterpretan completamente las consecuencias de este punto de vista si se entiende el lenguaje como puro medio expresivo entre sujeto y realidad. Lo que es lingüístico no es mero signo: es aquello que se comprende y que muchos 
pueden comprender de la misma manera. Ciertamente no es nada subjetivo. Comprender un enunciado no significa representarse el objeto al que este sustituye, sino comprender las reglas que determinan su correcta aplicación; la unidad primaria de las comprensiones no es el objeto, sino el enunciado mismo. La filosofía debe tomar como punto de partida del análisis no el nombre, sino el enunciado. De ese modo la vieja ontología se sigue manteniendo dentro de esta nueva perspectiva, como fundamento suyo, es decir, como la demanda sobre el significado de los términos singulares, y por tanto sobre su referirse a objetos. Se ha superado por tanto la gran limitación de la vieja ontología: la perspectiva objetual, la restricción del ámbito del discurso a los objetos.

La posición filosófica de Tugendhat no consiste en un giro de la fenomenología a la filosofía analítica, sino en una interpretación del fin de la metafísica como determinación linguística. El paso de la fenomenología a la filosofía analítica no es más que la aclaración linguíística de las condiciones transcendentales de toda experiencia: la metafísica se acaba con el giro lingüístico porque la aclaración de las cosas deja lugar a la aclaración de las palabras y de su disposición en los discursos humanos. Que el ser que puede ser comprendido sea el lenguaje no significa que el ser se identifique de ahora en adelante con el lenguaje, ni que la experiencia del mundo se lleve a cabo sólo dentro del lenguaje; y sobre todo no alude a un descubrimiento metafísico, sino sólo al saber de que el crecimiento de nuestra compresión tiene lugar a través del lenguaje. Tugendhat, Putnam, Kuhn, Pareyson, Davidson, Derrida, Habermas, Apel, Rorty, Vattimo, Nancy, Sellars o Brandom pertenecen al giro lingüístico del siglo XX. Este giro es el fin de la metafísica, es decir, del ojo de Dios, de la objetividad, del metalenguaje y de toda descripción privilegiada del ser. Si no hay modo de superar el lenguaje para alcanzar el objeto como es en sí, no sólo el ser que puede ser comprendido es lenguaje, sino que el terreno del lenguaje es él mismo un terreno a interpretar, por cuanto en él propiamente no existen hechos sino sólo enunciados verdaderos.

Tugendhat trata de responder a la siguiente pregunta: ¿qué significa pensar tras el giro linguístico? El giro lingüístico emprendido primero por Frege y Peirce, y luego por Wittgenstein y Heidegger, ha hecho posible no sólo la des-metafisicación de la teoría de la verdad como coherencia, sino también el fin de la disputa entre sujeto y objeto que tanto ha pesado sobre la indagación filosófica y científica, para poder analizar por fin el modo en que se justifican los asertos pro- 
posicionales. Gracias a este giro lingüístico, según Tugendhat, el modo de la referencia a los objetos no puede sino ser lingüístico, y la ontología se convierte en una semántica formal; en otras palabras, en una teoría del significado de los términos singulares capaz así de superar la metafísica de la presencia. Si con Rorty definimos el «nominalismo recurriendo a la tesis de Gadamer, por la cual sólo lo que es lingüístico puede ser comprendido" ${ }^{2}$, entonces Tugendhat es sin más un nominalista que trata de llevar la filosofía hacia un reconocimiento lingüístico de la comprensión. Aquí no hay traza alguna de la resistencia que los filósofos analíticos han venido siempre activando en contra de toda proveniencia histórica de la teoría; al contrario, para reivindicar la lingüisticidad del problema ontológico, Tugendhat reconstruye su historia.

Tugendhat se presenta al publico continental como el «abogado" de la filosofía analítica porque sostiene que la filosofía ha sido siempre, aunque sin haberse dado cuenta nunca abiertamente de ello, indagación linguiística; al público analítico en cambio le parece un "tradicionalista" porque sus indagaciones son un constante esfuerzo, no por ignorar la metafísica de la presencia (como en general hacen erróneamente los filósofos analíticos), sino de superarla. El pensamiento postmetafísico, originado por el giro lingüístico, se deriva de la identificación del horizonte de la comprensión con el horizonte lingüístico. En el ámbito de este giro el acento se pone sobre aquellos aspectos del lenguaje que se presumen positivos, sobre su dimensión pública, democrática, sobre su capacidad de asegurar la comunicación y, en último término, la transparencia en las relaciones interhumanas.

\section{El carácter hermenéutico de la fillosofía analítica}

Si el ser que puede ser comprendido es el lenguaje, la filosofía analítica no sirve ni para denunciar los problemas tradicionales de la filosofía como falsos problemas (esta es su originalidad en filosofía analítica), ni para aclararlos por medio de las explicaciones de las reglas de uso de las expresiones correspondientes, sino para comprenderlos mejor. La filosofía, según Tugendhat, no es la explicación de algo que no ha sido comprendido todavía, sino la clarificación de lo que ya ha sido comprendido; es decir, se trata de «desmantelar el lenguaje meta-

2 R. RORTY, "L'essere che può venir compreso è il linguaggio", en D. Di Cesare (ed.), L'essere, che pud essere compreso, è il linguaggio, Il nuovo Melangolo, Génova, 2001, pp. 45-59. 
fórico de la filosofía y sobre todo la metáfora de la vista que domina todo el pensamiento tradicional, puesto que es a esta metáfora fundamental a la que se puede remontar el empleo de todas las demás metáforas" ${ }^{3}$. Si el terreno del lenguaje es en sí mismo un terreno para interpretar, como sostiene Gadamer, entonces el enfoque basado en el sujeto, así como la orientación hacia el objeto, se ponen en contestación en la medida en que la compresión intersubjetiva dentro del lenguaje se convierte en el nuevo sistema de referencia universal. Formulado en términos tan generales, es este el mismo programa que el de la hermenéutica, pero en la filosofía analítica se lleva a cabo de una manera más elemental. Tras el fin de la metafísica, según Tugendhat, se abren dos posibilidades: la de la hermenéutica y la de la filosofía analítica. Ambas se encuentran en el terreno del lenguaje y se autointerpretan como filosofías postmetafísicas. Se puede considerar la filosofía analítica "como una hermenéutica reducida, como una hermenéutica puesta en primer plano. Le falta todavía la dimensión histórica y un concepto amplio de comprensión" ". El paralelismo entre filosofía analítica y hermenéutica se desarrolla sobre el plano de la metafísica, es decir, sobre los residuos metafísicos que caracterizan la fenomenología. Tal punto de partida consiste en presuponer que todas las cosas pueden considerarse desde una subjetividad pura y aislada, capaz de permitirnos, con un ojo mental ${ }^{5}$, captar esencias y universales. El así llamado ojo mental es común a toda la tradición metafísica, desde Platón hasta Husserl, el cual, con su teoría de la intuición eidética, le habría conferido un fundamento teórico. Pero a principios del siglo pasado Wittgenstein no sólo demostró que tal posibilidad se había clausurado, sino también que era una posibilidad inútil, desde el momento en que la filosofía no es más que comunicación. El sentido de la solución propuesta por Wittgenstein es el de corregir un enfoque equivocado, el enfoque que ha llevado a toda la tradición occidental a considerar el saber inmediato como algo fundado sobre una percepción comparable a la observación externa. Aclarar un concepto en la perspectiva intersubjetiva significa, según Tugendhat, explicar el uso (semántico y gramatical) de las palabras que corresponden a tal concepto. El significado de una palabra es su uso

${ }^{3}$ E. TUGENDHAT, Autocoscienza e autodeterminazione. Interpretazioni analitiche, La Nuova Italia, Florencia, 1997, p. 34.

${ }^{4}$ E. TugendHAT, "Fenomenologia e analisi linguistica», en S. Cremaschi (ed.), Filosofia analitica e filosofia continentale, La Nuova Italia, Florencia, 1997, p. 60.

5 Este es uno de los temas característicos de Heidegger en Ser y tiempo, $\$ 31$ : «Desde el principio, la tradición filosófica ha considerado el 'ver' como modo de acceso privilegiado al ente y al ser». 
en el lenguaje. El fin que esta tradición metafísica alcanza con la fenomenología "no significa el fin de la filosofía, sino el inicio de una nueva" ${ }^{6}$. Si la vieja filosofía se refería sólo $a$ aquello que podía ser visto claramente, la nueva filosofía se refiere sólo a lo que puede ser claramente comunicado. Toda la diferencia radica en un punto de vista distinto: sujeto aislado, puro, por una parte; comunicación intersubjetiva como médium originario y genuino de nuestra compresión por otra.

Según Tugendhat, el problema de la filosofía consiste en hacer explícito lo no explicito, es decir, el a priori. Este problema, que tradicionalmente es el problema de la aclaración de los conceptos, acompaña toda la historia de la filosofia. Mientras las ciencias indagan hipótesis y conceptos empíricos, la filosofía debe aclarar, hacer explícitos aquellos conceptos que pertenecen a la totalidad de nuestra compresión. Es preciso pasar del énfasis dado a las condiciones trascendentales de toda experiencia posible a la aclaración lingüística de tal experiencia. Pero el problema consiste en la explicitación de conocimientos no explícitos; los conocimientos implícitos son siempre, al contrario que los a posteriori, susceptibles de una ulterior iluminación e interpretación. Tugendhat sostiene que los conceptos que condicionan nuestra comprensión (a priori) pueden ser aclarados sólo mediante la reflexión, la reflexión sobre lo ya dado. Husserl y la fenomenología piensan en cambio que esta reflexión es sólo intuitiva: por ello consideran que los conceptos a priori pueden comprenderse como esencias que se ven interiormente. En realidad, la única alternativa es la lingüístico-analítica, tal y como ha sido desarrollada por Wittgenstein. Dentro de tal alternativa todo concepto es una forma de utilizar una experiencia lingüistica. No comprender un concepto a priori significa no dominar las reglas gramaticales que expresan tal concepto. El significado de una expresión es lo que se explica cuando se explica el modo en que tal expresión se utiliza.

$\mathrm{Si}$, como piensa la hermenéutica, es la proveniencia ${ }^{7}$ la que promueve la argumentación, la filosofía analítica y la hermenéutica comparten el mismo carácter

${ }^{6}$ E. Tugendhat, «Description as the Method of Philosophy. A Reply to Mr. Petrit», en Philosophische Aufsätze, Suhrkamp, Fráncfort del Meno, 1992, p. 415.

7 «Es la proveniencia (específica de la filosofía como actividad marcada por cierta historia en la tradición cultural europea) la que lleva la filosofía a la argumentación; y es la misma la que le ofrece el repertorio de sus argumentos, los únicos a los que puede recurrir». G. VATTIMO, Diritto a l'argomentazione, en G. Vattimo (ed.), Filosofia '92, Laterza, Roma-Bari, 1993, p. 70. 
y programa. ¿ En que consiste este programa? Según Tugendhat el carácter hermenéutico de la filosofía analítica consiste a) en «reconocer el propio lenguaje como relativo y limitado», b) en tener por inútil el recurrir a un "metalenguaje», c) en la imposibilidad de observar nuestra comprensión a través de cualquier ojo mental. Esta compresión sólo puede ser «explicada reflexivamente» sin poder ser nunca observada. Esta no constituye una conciencia trascendental, ni una conciencia supramundana, sino una comunidad lingüística que existe empíricamente. Estas características pertenecen todas a una transformación filosófica que reconoce su propio cariz hermenéutico, esto es, postmetafísico.

Los conceptos tematizados por la filosofía son interdependientes, porque más allá de ser constitutivos de nuestra comprensión en su totalidad, constituyen una red para comprender nuevos horizontes lingüísticos. La filosofía tiene la función de aclarar esta red; establecer qué relaciones recorren y pueden recorrer estos conceptos significa construir expresiones artificiales, es decir, inventar nuevas palabras. Este último aspecto distingue la filosoffa del lenguaje de la lingüistica, es decir, la semántica filosófica de la semántica lingǘrstica. La semántica lingüística es prisionera de la objetividad porque considera esencial construir un metalenguaje (que normalmente es siempre el suyo) capaz de decidir la importancia de cada una de las expresiones lingüísticas. Este metalenguaje funciona como el ojo mental de la fenomenología: no necesita inventar nuevas palabras porque posee ya un lenguaje artificial capaz de ver más bien que de aclarar, capaz de adaptar más bien que de explicitar. A la pregunta de por qué debería la semántica filosófica inventar nuevas palabras, Tugendhat responde que los conceptos constitutivos de nuestra comprensión lingüistica no pueden estar contenidos en palabras separadas, sino que requieren estructuras lingüísticas completas; Aristóteles, por ejemplo, inventó las palabras sujeto y predicado para tematizar la estructura predicativa de nuestra comprensión. «El sentido de todo esto es que lo ya comprendido sea aclarado $y$, de esta forma, se haga explícito»"

El nosotros, como ya hemos dicho, no es ni una consciencia trascendental, ni cualquier conciencia supramundana, sino una unidad lingüística empíricamente existente, determinada por el hecho de que nuestra comprensión tiende a comunicar más que a definir. Confrontarse con nuevas comunidades lingüisti-

${ }^{8}$ E. TUGENDHAT, "Überlegungen zur Methode der Philosophie aus analytischer Sicht», en Philosophische Aufsätze, cit., p. 267. 
cas significa «la apertura de nuevas posibilidades de comprensión que podamos eventualmente incorporar en un "nosotros" más amplio. Fin de la metafísica significa también fin de la modernidad, es decir, fin de todo posible metalenguaje cultural» ${ }^{9}$. Que nuestro lenguaje sea esencialmente predicativo no significa que también todos los demás lenguajes deban ser predicativos. Un lenguaje no predicativo es ciertamente posible. Si encontrásemos tal lenguaje no se seguiría la falsación de todo cuanto hemos afirmado hasta ahora, sino la ampliación de la posibilidad de la comprensión humana, de igual manera que la comprensión del "espacio" ha sido ampliada con el descubrimiento de los espacios no euclidianos. Comprender mejor una cosa no es sino tener algo más que decir sobre ella, estar en grado de unir las diversas cosas dichas anteriormente de un modo nuevo y claro. Según Tugendhat, el lenguaje de los otros es sobre todo una potencial ampliación del lenguaje propio; por lo tanto, debe tematizarse en segunda persona (no en tercera persona, tal y como sucede en la lingüística objetivista, la cual de este modo, en vez de entrar en diálogo con los lenguajes de los otros, se limita a hablar de ellos). Si la filosofía es comunicación, es necesario tratar los lenguajes de los otros como se trata el propio, hablar con ellos, nunca de ellos.

\section{La disolución de la ontología en la semántica formal}

La filosofía es eminentemente ontología, reflexión sobre el ente en cuanto ente; pero al contrario de lo que sucede en la ontología tradicional, el desplazamiento de la ontología hasta el plano del lenguaje, es decir, hasta el plano del giro lingüístico, significa que el problema de los objetos en calidad de objetos se plantea en verdad cuando se nos interroga sobre el modo en que nos referimos a ellos. Este desplazamiento de la ontología al plano del lenguaje nos lleva, más allá de la ontología de la presencia, hacia una filosofía analítica del lenguaje que "contiene en sí la idea de una semántica formal capaz de asumir la herencia de la ontología y la filosofía trascendental».

En la Introducción a la filosofia analitica ${ }^{10}$ Tugendhat sienta las bases para una concepción que, bajo el nombre de semántica formal, asigna a la filosofía el papel

9 Para un encuadre histórico y conceptual del fin de la metafísica y del advenimiento de la postmodernidad remito a W. WELSCH, Unsere postmoderne Moderne, Akademie Verlag, Berlín, 1997; y G. Vattimo, La fine della modernità, Garzanti, Milán, 1985.

${ }^{10}$ E. TUGENDHAT, Introduzione alla filosofia analitica, Marietti, Génova, 1989. 
de disciplina fundamental. Dentro de esta concepción sistemática, el concepto metodológico que se destaca consiste en la idea de que un concepto puede aclararse sólo si se hace referencia a la regla de uso de la palabra correspondiente. En otras palabras, comprender el significado de una palabra no significa ver algo: "No hay nada que ver en una palabra", dice Tugendhat,

e incluso si lo hubiese, no te ayudaría para una comprensión intersubjetiva; muestra más bien cómo se emplea esa palabra. [...] Se trata por lo tanto de desmantelar el lenguaje metafórico de la filosofía y sobre todo la metáfora de la vista que domina todo el pensamiento tradicional, puesto que desde esta metáfora fundamental es desde donde se puede reclamar la utilización de todas las otras metáforas. ${ }^{11}$

Tugendhat señala aquí la vía a través de la cual cabe eliminar la centralidad de cualquier teoría del conocimiento, y salir de la trampa metafísica de la objetividad; para ello, se puede recurrir, por una parte, a la teoría semántica de Frege, según la cual «un nombre tiene significado sólo en el contexto de un enunciado", y, por otra, a la filosofía analítica, que considera la comprensión como un hecho lingüistico. La reflexión lingüística no sólo debe demostrar que todo lo que hay son enunciados verdaderos y no hechos, sino también que toda nuestra comprensión es comprensión lingüística.

La interpretación lingüistica que hace Tugendhat parte del libro IV de la Metafisica de Aristóteles. No obstante sus tensiones internas, la ontología aristotélica ha sido la base de una tradición de pensamiento dirigida al objeto; al hacer esto, ha privilegiado un tipo de expresiones lingüisticas, términos singulares, nombres propios y descripciones definidas. La filosofia analítica vuelve a dar importancia a otros tipos de expresiones lingüísticas, a los términos predicativos y a los enunciados. Si se sigue el camino de Aristóteles y se construye la filosofía como ciencia primera, deducida de las ciencias singulares y formalmente común a todas, este elemento formal no puede ser la objetividad, porque nuestra referencia a los objetos está ella misma constituida por asertos predicativos: la teoría de los objetos es parte integrante de la semántica formal.

1 E. Tugendhat, Autocoscienza e autodeterminazione, cit., p. 34. 
La característica metafísica de la ontología tradicional consiste en la tendencia platónica a sustancializar los predicados concibiéndolos como objetos abstractos; a pasar, por ejemplo, de "el cielo es azul" a ulo azul del cielo". Toda nominalización de una expresión equivale a una objetualización: el «azul" se convertía en lo «azul». El significado de las expresiones lingüísticas se ha venido concibiendo objetivamente. En otras palabras, todos los pasos decisivos son el resultado de una "reinterpretación objetivadora" que ha mantenido escondida la dimensión lingüística de la reflexión. Platón, reflexionando sobre el problema de las definiciones, ha descubierto por primera vez los significados de los predicados, y en su doctrina de las ideas los ha objetivado en entes ultrasensibles. Aristóteles, a su vez, ha partido de la forma del enunciado predicativo singular, y sobre esta base ha elaborado una ontología objetiva. La reflexión filosófica sobre el lenguaje no sólo muestra que la verdad reside exclusivamente en los enunciados y no en los hechos, sino también que toda nuestra comprensión de la verdad es comprensión lingüistica. De Platón y Aristóteles, hasta Husserl y Heidegger, la concentración sobre el objeto ha impedido una comprensión adecuada de la forma "proposicional predicativa" porque ese referirse de un término singular a su objeto dentro de un juicio es considerado una "correlación" (Zuordnung) de dos planos diversos. Por el contrario, en el lenguaje esta síntesis de los dos elementos diversos no debe realizarse de hecho, porque el lenguaje requiere para ser comprendido que no se lo abandone nunca. Tugendhat sostiene que incluso si el término lingüístico está en el lugar de un objeto, este objeto

no es accesible extralingüísticamente. [...] La idea de una atribución presupone que el objeto sea accesible también extralingüísticamente. En cambio, [...] la referencia a un objeto espacio-temporal es comprensible sólo como indicación sobre cuál de todos los objetos presentes dentro de la totalidad espacio-temporal es el objeto en cuestión, y esto sólo es posible sobre la base de un complejo sistema de reenvíos compuesto por expresiones deícticas (demostrativas) que localizan espacio-temporalmente. Puesto que en general se puede hacer referencia a un objeto sólo refiriéndose a todos los objetos, la utilización de los términos singulares se muestra sustancialmente más complicada que la utilización de los términos generales, contrariamente a los prejuicios tradicionales $^{12}$.

\footnotetext{
12 E. TugendHAT, Introduzione..., cit., p. 6.
} 
Tugendhat parte del presupuesto de que todo el pensamiento es un hecho lingǘstico, y de que la esencia del lenguaje reside en el uso; por este motivo, la semántica formal debe introducirnos en el correcto uso del lenguaje. El lenguaje no es un simple médium entre nosotros y la realidad de los objetos, ya que en su tejido semántico están incluidas determinaciones que no dependen de la mera objetividad y que sin embargo contribuyen a su comprensión.

La teoría semántica de Frege ayuda a la filosofía a liberarse del vínculo tradicional con los objetos, es decir, a pasar de preguntas del tipo "En el lugar de qué objeto está esta palabra?» a preguntas del tipo «¿Cómo poner juntas las palabras?». Si continuamos preguntando a qué objeto de la representación se refieren las palabras, no lograremos nunca, según Tugendhat, reconocer en el lenguaje la esfera peculiar de la filosofía. Las preguntas objetivistas, metafísicas, presuponen que nuestra comprensión del lenguaje viene precedida por la comprensión de la relación entre el lenguaje y algo distinto (el mundo, la realidad). Esta orientación hacia los objetos ha obligado a la ontología tradicional a formular su pregunta más difícil, a preguntarse qué es el ente en cuanto ente. Tal pregunta debe reformularse ahora si se quiere evitar el hablar del significado como si fuera un objeto. Por eso se pregunta cómo se pueden referir los objetos a expresiones lingüísticas, y qué significa comprender un término singular. Determinar de esta manera la temática de la filosofía significa relacionar todos los conceptos específicamente filosóficos con estructuras linguísticas analizables; de esta manera, la esfera del a priori de la aclaración del significado se restringe a las estructuras de la comprensión presupuestas en toda comprensión de expresiones linguísticas singulares». Hemos visto que la ontología tradicional tenía ya en sí una perspectiva sobre la semántica formal, sobre la forma de los enunciados; Aristóteles mismo se había orientado de hecho hacia el logos, el lógos apophantikós, el enunciado asertivo. La pregunta ontológica, entonces, debe encontrar una formulación adecuada también en la semántica formal. Ahora bien, si la semántica debe considerar atentamente la forma de todos los enunciados o bien la conexión de todas las formas enunciativas que se pregunten qué significa comprender un enunciado, la pregunta sobre el ente en cuanto ente, reformulada en términos semánticos, preguntará qué se trata de decir cuando se habla del ente. La nueva pregunta fundamental de la filosofía, "Qué significa comprender un enunciado?» nos ayudará a evitar que el predicado y el sujeto de las proposiciones se refieran a objetos representados por ellos. Si comprender un enunciado no significa representarse el objeto al que este sustituye, la única posibilidad que que- 
da es comprender las reglas que determinan su empleo correcto; en efecto, "el enunciado es la unidad primaria del significado" ${ }^{13}$.

\section{No existen hechos, sólo enunciados verdaderos}

El enunciado, dice Tugendhat, siempre ha sido considerado como una síntesis de dos elementos, sujeto y predicado, de la cual brotaría el significado. Si la referencia al objeto se produce sólo a través del término singular, y este último debe formar parte inevitablemente de un enunciado, entonces el término singular debe ir siempre acompañado de un predicado. La función del predicado no es la de vicario, sino la de caracterizar ese algo que está contenido en el término singular; comprender un predicado significa por tanto comprender su función.

Si el significado de un enunciado no es la representación de un estado de cosas, entonces la explicación de ese estado de cosas depende exclusivamente del enunciado y de su significado, o sea, de la comprensión del enunciado no nominalizado. El nominalista negará que el predicado indique algo fuera del uso que se hace de él en el juicio. "Tomemos el enunciado "el castillo de Heidelberg es rojo". Si proferimos este enunciado en la situación en la que percibimos el castillo y percibimos que es rojon, explica Tugendhat,

lo haremos sobre la base de una explicación del color. Pero supongamos en cambio que proferimos este enunciado en una sala como ésta, donde no podemos ver el castillo; entonces puede que tengamos una representación correspondiente del color en la imaginación, pero podremos evidentemente comprender de igual modo el enunciado sin tener una representación que corresponda a la palabra "rojo" ${ }^{14}$.

El predicado (es rojo) no une el objeto designado por el término singular (el castillo de Heidelberg) a una característica objetiva (la rojez), sino que determina el objeto según un carácter que pertenece al objeto mismo. La verdad del

13 Ibid., p. 46.

${ }^{14}$ E. TUGENDHAT, Vorlesungen zur Einführung in die sprachanalytische Philosophie, Suhrkamp, Fráncfort del Meno, 1976, p. 184-185. 
enunciado al completo no dependerá por tanto del objeto, sino del significado de las partes que componen el enunciado. Podemos hacer notar a alguien qué indica la palabra "rojo" no porque podamos referirnos al rojo como a un objeto, sino porque podemos indicarle, recurriendo a ejemplos positivos y negativos, qué uso hacemos de esta palabra. Se habrá comprendido el significado de la palabra cuando nuestro interlocutor la use del mismo modo. No es necesario que se recurra a representaciones generales. La prioridad que Tugendhat asigna a la forma predicativa (es rojo) contra la nominalización (la rojez) está ligada a la polémica antiplatónica; según la tradición nominalista, el predicado no corresponde a algo general, porque no existe nada general. Los únicos signos de los que podemos servirnos para comprender son los signos mismos, los nomina. Esto equivale a decir que ninguna descripción de un objeto es más conforme a la naturaleza de aquel objeto que cualquier otra descripción.

Gracias al "principio fundamental de la filosofía analítica», el nominalismo no corresponde ya a una proposición escéptica, sino que contiene también la posibilidad de explicar positivamente los predicados independientemente de los objetos. Este principio fundamental, dice Tugendhat, consiste en la formula de Wittgenstein según la cual "El significado de la palabra es aquello que se explica por la explicación del significadon ${ }^{15}$. Si se quiere aclarar el significado con que se usa la palabra "rojo", para que "la rojez" pueda ser representada en general, sería inútil apelar a esta: incluso a uno mismo sólo le resulta posible explicarse un predicado recurriendo al uso que en el juicio se hace de él sobre la base de la comprensión personal. La comprensión de los nombres «lo rojo" o "la rojez" se funda sobre la comprensión del predicado «rojo»; en cambio lo contrario no es verdadero. Términos singulares como «lo rojo» o "la rojez» no son más que la nominalización del predicado «rojo». Cuando decimos que el castillo es rojo, no lo hacemos pensando que ese objeto deba ser colocado bajo la percepción del rojo. La verdad de un enunciado predicativo depende del hecho de que el predicado caracteriza correctamente al objeto designado por el término singular, objeto que está enteramente referido al nombre que lo designa y que no comparece nunca en carne y hueso. La filosofía analítica, como semántica formal, no busca los objetos a los que las expresiones lingüísticas se refieren en el uso que hacemos de ellos; no trata por tanto de construir una metafísica, sino

${ }^{15}$ L. WiTtgensteIn, Philosophische Untersuchungen / Philosophical Investigations (edición de G. E. M. Ascombe y R. Rhees), Basil Blackwell, Oxford, 1953. 
que trata tan sólo de volver a la conciencia prefilosófica a la que pertenecen los significados.

El enunciado asertivo es verdadero cuando el predicado es inherente al objeto designado por el término singular sin que esta inherencia descienda de una síntesis cualquiera de los dos elementos del enunciado. Dice Tugendhat: "La aserción de que $a$ es $F$ es verdadera sólo si el predicado $F$ es inherente [zutrifft] al objeto designado por el término singular». ¿Qué significa "ser inherente»? El predicado (rojo) es "inherente" al objeto (el castillo de Heidelberg) sólo si el castillo de Heidelberg es rojo. La proposición es un complejo formado por los significados de los dos elementos que la componen, o sea, término singular y predicado. $\mathrm{El}$ estado de cosas se comprende a través de la proposición. Puesto que la relación con los objetos se lleva a cabo sólo a través del lenguaje, el significado de un enunciado puede ser verificado sólo dentro del lenguaje mismo. En el caso de un enunciado predicativo, el camino seguido para la verificación es el de la identificación del objeto designado por el término singular: la última etapa de este camino es la verificación en la percepción, verificación que a su vez encuentra expresión en una proposición y no contiene ninguna referencia general.

Platón ha sido el primero, según Tugendhat, en mostrar que la posibilidad de lo verdadero y lo falso depende de la estructura predicativa; pero para él se trata sólo de explicar la posibilidad de lo falso, de explicar de este modo cómo es posible afirmar algo de lo que no es. La referencia al no-ser ha permitido a Platón descuidar el hecho de que los dos componentes de la proposición tienen funciones diversas. En la tradición esta diversidad no se ha notado porque se da por descontado que ambos componentes tienen la función de sustituir a un objeto. Desde hace tiempo se cree que lo que hace posible la relación con la verdad del lenguaje es la referencia a objetos. La filosofía tradicional da por obvia esta referencia, hasta el punto de no considerarla un problema. Ahora bien, si la verdad del predicado "rojo" no remite a la rojez o a lo rojo entendidos como objetos, entonces su inherencia respecto al término singular (el castillo de Heidelberg) es de naturaleza puramente lingüística. La verdad de predicado "rojo" no depende ni de la percepción del color ni de la evocación del color en la fantasía: el enunciado es verdadero o falso en función del significado de los elementos que lo componen, no en función de la síntesis de propiedades de los objetos reales o imaginados. El significado de un predicado indica una función referida siempre $y$ exclusivamente al término singular. 


\section{El lenguaje es la conciencia del sujeto}

Si la repetición del problema del ser por parte de Heidegger ha llevado a la interpretación del sentido (verdad) del ser como apertura, y esta apertura debe incluir el lenguaje, entonces a) la conciencia es una conciencia proposicional que se refiere no a objetos sino a proposiciones; y b) la autoconciencia es la relación de una persona con respecto a proposiciones. Toda conciencia intencional es, según Tugendhat, explícita e implícitamente conciencia proposicional, porque aprehender la indicación de un objeto no es sólo un componente de la comprensión de enunciados predicativos, sino que se basa ella misma en una conciencia proposicional, en considerar verdadero un enunciado de existencia " ${ }^{16}$. La relación intencional, como se entiende en la fenomenología, está fundada ella misma sobre la comprensión de un enunciado, porque no hay ninguna conciencia que no esté fundada sobre el tener por verdadero un Existenzsatz. Esta propiedad particular de la conciencia, que Husserl denominó «intencionalidad» e indicó, prolongando la descripción intuitiva, que se dirige hacia los objetos, se revela ahora un Satzverständnis,

porque tampoco el discurso sobre la conciencia como una relación sujeto-objeto, tan amado por la filosofía trascendental, es aceptable. No hay tal relación. Donde un sujeto se refiere conscientemente a un objeto, no hay nunca una simple relación, sino que esta está siempre fundada sobre una comprensión de enunciados. Entre lo fatales efectos provocados por la idea de urelación sujeto-objeto» se encuentra sobre todo la tentativa, dentro del idealismo alemán, de comprender según este esquema también la autoconciencia ${ }^{17}$.

La autoconciencia se entiende la mayor parte de las veces como una relación en la que el sujeto se considera a sí mismo como objeto; el «sujeto» esta protegido con expresiones que no pertenecen al lenguaje ordinario, sino que derivan de la sustantivación de determinaciones lingüísticas tales como "conciencia», "yo", «sí mismo".

En Autoconciencia y autodeterminación ${ }^{18}$, Tugendhat parte del presupuesto de que para hablar de la autoconciencia se debe renunciar a la idea de alguna per-

\footnotetext{
16 E. TUGENDHAT, Introduzione..., cit., p. 87.

17 Ibíd., p. 88.

18 E. Tugendhat, Autocoscienza..., cit., p. 34.
} 
cepción interna; cuando Husserl llama la atención sobre las experiencias intencionales vividas, en realidad se trata del modo en que nos referimos en el lenguaje a los fenómenos. La peculiaridad de las palabras sobre las que la metafísica ha llamado nuestra atención es una peculiaridad semántica, ya que "conciencia de algo", "autoconciencia", "yo" son determinaciones que se constituyen primeramente en el lenguaje.

La argumentación de Tugendhat es la siguiente: a) «cierto objeto existe» es una proposición; b) mantener que el objeto en cuestión existe es una conciencia proposicional; y c) toda conciencia intencional se refiere a objetos proposicionales o implica un conciencia proposicional. El hecho de que mi acceso a la existencia de los objetos suceda invariablemente en proposiciones no me autoriza a sostener la hipótesis de mi existencia fuera del lenguaje. La autoconciencia no es la conciencia que yo tengo de mí mismo, sino ese saber conceptual que se concreta en una proposición mediante la cual me atribuyo cierto "predicado $\varphi$ ", donde " $\varphi$ » es un predicado que indica un estado de conciencia. La autoconciencia "posee o implica la estructura "ser consciente de que p" "19. Contrariamente a los modelos propuestos en las doctrinas tradicionales, el sujeto no posee ningún acceso directo ni a sí mismo ni a sus propios estados mentales, porque sólo puede articular sus experiencias vividas en proposiciones del tipo: "Yo sé, siento, me doy cuenta de, que yo p". El sujeto no puede tener un saber ni de su "yo" ni de sus estados considerados aisladamente, sólo puede saber que se encuentra en este o en aquel estado. Conciencia y autoconciencia no son fenómenos de naturaleza objetiva, sino lingüística, porque la autoconciencia es un saber que se expresa en forma de enunciados. El sujeto se halla completamente reabsorbido en el lenguaje, en las proposiciones: la conciencia del sujeto es el lenguaje.

Dado que se puede identificar un sujeto al percibirlo sólo si al mismo tiempo se le reconoce como el portador de ciertos predicados, no hay ninguna objetividad independiente del lenguaje, porque lo que hemos designado como «objetividad" o "estado de cosas" no puede ser constatado sin referirse a las proposiciones y a sus significados: un objeto sólo puede tener significado dentro de un lenguaje, porque el significado no es más que una parte constitutiva y dependiente del uso

19 Ibíd., p. 14. 
de los signos. Igual que no es necesario intuir el castillo de Heidelberg para constatar que es rojo, no se pueden observar las relaciones de conciencia como ael saber", "el desear", "la tristeza"; y ello porque el sujeto gramatical ya no es una expresión que caracteriza un objeto espacio-temporal, sino una proposición objetiva.

La reformulación de las teorías metafísicas de la autoconciencia a la luz del giro linguístico permite a Tugendhat evidenciar el aspecto comunicativo y veritativo del sujeto, dejado de lado por el planteamiento que se orientaba en dirección a los objetos. El único acceso posible a los fenómenos es aquel que se da a través de las reglas de uso de las correspondientes expresiones predicativas; el objeto por el que puede estar la expresión "el folio", no es un objeto espacio-temporal: el folio se encuentra ahora aquí, es verdad, pero el hecho de que ahora se encuentre aquí, este estado de cosas no posee a su vez un lugar preciso en el tiempo y en el espacio. El estatuto ontológico de los objetos tras el giro lingüístico reposa sobre una conciencia proposicional, es decir, sobre una relación consciente no con los objetos, sino con las proposiciones.

El pensamiento tradicional no ha sabido, según Tugendhat, extraer de las diversas funciones que las palabras tienen dentro del lenguaje ninguna indicación que pudiese servir para el cuestionamiento filosófico. La reflexión lingüística que falta en la historia de la filosofía ha tenido como consecuencia la objetivación de determinaciones que en realidad pertenecen al lenguaje. La metafísica ha creído que los nombres eran signos por medio de los cuales se puede hacer referencia directa a los objetos, mientras que estos, en calidad de términos singulares, son simplemente los medios verbales a través de los cuales el hablante puede indicar a qué elemento se refiere en el discurso. El término singular, como ya hemos visto, es una expresión cuya función consiste en designar un objeto particular, en indicar de este modo a qué objeto se hace referencia entre todos los posibles. El término singular indica el objeto al que "se aplica» la expresión predicativa que, unida al término singular, forma el enunciado completo; si digo "Tugendhat es alemán" con el término singular "Tugendhat» indico el objeto del que quiero decir ahora que es alemán. El giro lingüístico de la filosofía ha mostrado hasta qué punto ha venido concibiendo la ontología los problemas filosóficos mediante metáforas modeladas principalmente sobre el acto de ver, incluida la metáfora de los objetos que, indicados por nombres, se encuentran fuera de la conciencia. 
Según Vattimo «la tarea de la filosofía es, tras la deconstrucción, un trabajo de recosido y de recomposición ${ }^{20}$, desde el momento que la metafísica no puede ser superada, überwunden, sino sólo aceptada y retomada, verwunden. La filosofía analítica, como la entiende Tugendhat, no es tanto una propuesta contra todo retorno a la metafísica cuanto una crítica a la terminología filosófica que sigue todavía ligada a la referencia a los objetos. En este sentido, ella le ha servido a Tugendhat sobre todo para disolver esos problemas filosóficos en que todavía se deja asomar la ilusión de que la filosofía tiene un ámbito propio de objetos fuera del lenguaje. Si para la hermenéutica «no existen hechos, sino sólo interpretaciones", para la filosofía analítica "no existen hechos, sino sólo enunciados verdaderos". Ciertamente, no es la división entre analíticos y continentales la que ha contribuido a individualizar la posición filosófica de Tugendhat, sino el fin de la metafísica, es decir, el fin de la época de la imagen del mundo ${ }^{21}$.

${ }^{20}$ G. VATTIMO, «Prefazione», en F. D’Agostini, Analitici e continentali. Guida alla filosofia degli ultimi trentáann, Milán, Raffaello Cortina Editore, 1997, p. XV.

${ }^{21}$ M. HeIDEGGER, "Die Zeit des Weltbildes», en Holzwege, Klostermann, Fráncfort del Meno, 1950. 